\title{
Reliability Analysis with Renewable DGs for Loss Reduction in Radial Distributed Generation
}

\author{
R. Kavyasree ${ }^{*}, J$. Sridevi² and $V$. Usha Rani ${ }^{3}$. \\ ${ }^{1}$ Student, EEE Department, Gokaraju Rangaraju Institute of Engineering and Technology, Hyderabad, India \\ ${ }^{2}$ Professor, EEE Department, Gokaraju Rangaraju Institute of Engineering and Technology, Hyderabad, India \\ ${ }^{3}$ Asst.Prof. EEE Department, Gokaraju Rangaraju Institute of Engineering and Technology, Hyderabad, India
}

\begin{abstract}
Nowadays, in the Evolving Power System, reliability testing plays an important role in the design and implementation of distribution systems that operate in a cost-effective manner with minimal customer load disruption. The distributed generation (DG) will play a major role in emerging Power systems as they use a variety of resources and technologies to harness energy in Power systems by reducing Power losses while maintaining the Voltage profile in the system within the limits set. In this paper, two case studies with one DG and two DGs were analysed. The results obtained showed that the DG Number with the plan will increase the reliability of the joint system. The proven system is verified before the IEEE 6-Bus Radial Distributed System to reflect exposure and impact on ETAP software.
\end{abstract}

\section{Introduction}

The DG (Distributed Generation) has been growing rapidly in reduced power systems resulting in their potential solutions to meet local needs at the distribution level and to reduce limited transmission power from central power stations[1-2]. The entry of the DG into the existing distribution system has many imputations for the system. However, incorrect size as well as arrangement of the units of weight units in a power system can jeopardize a reliable system performance[3] As a result, a good location and DG size should be established for the network distribution infrastructure In power systems, reliability analysis is defined as system flexibility analysis to satisfy load requirements [4-5]. The calculation of the reliability of a complete system depends on the reliability of all components included in that system. Each section has 2 locations, working conditions and unsuccessful conditions[6]. By specifying whether a component is active or not we will select the order of the program. reliability analysis and square measure assessment are key factors in the continuous performance of the system The main objective is to measure the effect of DG on the reliability of the system[7-8]. The IEEE 6-Bus distribution network was used in the study. [9] The precision and size of the DG have been changed, the insect particle development and the ETAP software packages have been used for model analysis and reliability [10-11].

There has been developing interest in renewable energy from renewable resources due to the need for extra electricity, global warming and therefore a strong elimination of fossil fuels. The onset or arrival of an expected energy source from a renewable source[12-13]. sources is likely to be a more reliable answer to the question than one perceived. Therefore, analysis before the merging of DGs into a distribution network is very famous [14-15]. Indeed, the position of the DG is the best place to live or work and the appropriate size bequeath in one can make different edges on the whole power such as living force lost or lost object and line deceleration, smooth reduction and sensitivity of the power profile [16].

Wind energy is a common high-performance renewable DG because it occurs as a rapidly growing energy source from renewable energy sources as it is a low energy cleaner and also requires minimum time to establish. Air production is happening very fast as part of a full-fledged news feed [17]. The ideal power supply for system winds on the earth's surface is $1.6 \times 107 \mathrm{MW}$ approximately, which is equivalent to the energy produced by the earth's crust. Wind power exists as a result of expected delivery, because the size and location of the living or the production of wind farms constitutes a suitable disposal relationship[18-19].

Solar energy can be a superior source of energy and carry a large amount of energy in the form of an infinite energy source[20]. Its capacity is 178 billion MW, which is 20,000 times more than the demand for land. Solar energy can be used as photovoltaics[21]. PV systems can be used to provide a wide range of energy sources: fashionable homes, public spaces, limited businesses, crop production, health care, and available water. Another part of the PV action grid action, is usually as distribution units are distributed[22]. Due to the critical nature of the loads, the current system value exceeds its production capacity which makes connectivity resources unavailable and therefore a robust system structure cannot be exceeded. In a systematic way, in order to

\footnotetext{
* Corresponding author: kavyasree.rudroju@gmail.com
} 
meet the required level of demand, renewable DG units are created by an intelligent distribution network to create or enhance a potential profile, support unreliable and uninterrupted power supply and in addition to achieving economic objectives thereby reducing equity losses [23].

\section{Evaluation of Reliability}

Term fidelity refers to the ability of a system to perform its joint function, and previous study helps to measure the future performance of a system. Integrity is the possibility of something happening to a device or system that participates in the task of attracting a presentation appropriately, among other things, for a special purpose. The results from reliable research may mean using various reliability indicators. There are many access pointers available that often cooperate. In order to indicate the difficulty or significance of the end of the plan, the reliability indicators are calculated. Depending on the application, a suitable set of indices should be selected, to make a fidelity decision. It is possible that a low-level approach somehow cleared the electrical services industry to work with standard IEEE reliability indicators such as SAIDI, SAIFI, AENS to track and measure performance reliability. These reliability indicators include steps for end events, frequency of travel, system opportunity and response time. The general flow of reliance indicators determines distribution engineers whose facts are linked to the expected range of annual levels. Testing from a reliable composite index of a complex system requires more than a computer.

Below Equations used to calculate load point as well as system indices :

$$
\begin{aligned}
& \lambda_{P}=\sum_{\mathbf{i}=\mathbf{1}}^{\mathbf{N}} \lambda_{\mathbf{i}}\left(\frac{\mathbf{f}}{\mathbf{y}_{\mathbf{r}}}\right) \\
& \mathbf{U}_{\mathbf{P}}=\sum_{\mathbf{i}=\mathbf{1}}^{\mathbf{N}} \lambda_{\mathbf{i}} \mathbf{r}_{\mathbf{i}} \frac{\mathbf{h}_{\mathbf{r}}}{\left.\mathbf{y}_{\mathbf{r}}\right)} \\
& \mathbf{r}_{\mathbf{p}}=\frac{\mathrm{U}_{\mathrm{P}}}{\lambda_{\mathbf{P}}}\left(\mathbf{h}_{\mathbf{r}}\right)
\end{aligned}
$$

Here, the component(I) failure $\operatorname{rate}\left(\lambda_{\mathrm{i}}\right)$ average $\left(\mathrm{r}_{\mathrm{i}}\right)$, repair time $\left(\mathrm{I}_{\mathrm{p}}\right)$, Unavailability $\left(\mathrm{U}_{\mathrm{p}}\right)$ and average failure rate $\left(\lambda_{\mathrm{p}}\right)$ at load point $\mathrm{p}$.

System Average Interruption Duration Index

$$
\begin{aligned}
& \text { SAIDI }=\frac{\text { sum of customer interruption index }}{\text { total number of customers served }} \\
& \text { SAIDI }=\frac{\sum_{i=1}^{k} U_{i} N_{i}}{\sum_{i=1}^{k} N_{l}}
\end{aligned}
$$

System Average Interruption Frequency Index

$$
\mathrm{SAIFI}=\frac{\text { total number of customer interruptions }}{\text { total number of customers served }}
$$

$$
\mathrm{SAIDI}=\frac{\sum_{i=1}^{k} \lambda_{i} N_{i}}{\sum_{i=1}^{k} N_{i}}
$$

Average Service Availability Index

ASAI $=$

total number of customer hours available during a year total customer hours demanded

$\mathrm{ASAI}=\frac{\sum_{i=1}^{k} 8760 N_{i}-\sum_{i=1}^{k} U_{i} N_{i}}{\sum_{i=1}^{k} 8760 N_{i}}$

Average Service Unavailability Index

$\mathrm{ASUI}=\frac{\text { total number of customer hours not available }}{\text { total number of customers hours demamnded }}$

$$
\mathrm{ASUI}=1-\mathrm{ASAI}
$$

Customer Average Interruption Duration Index

$$
\begin{aligned}
& \text { CAIDI }=\frac{\text { sum of customer interruption durations }}{\text { total number of interrupted customers }} \\
& \text { CAIDI }=\frac{\sum_{i=1}^{k} U_{i} N_{i}}{\sum_{i=1}^{k} \lambda_{i} N_{i}}
\end{aligned}
$$

Energy Not Supplied Index

$\mathrm{ENS}=\sum_{i=1}^{k} U_{i} L_{a(i)}$

Average Energy Not Supplied Index

$$
\begin{aligned}
& \text { AENS }=\frac{\text { total energy not supplied }}{\text { total number of customers served }} \\
& \mathrm{AENS}=\frac{\sum_{i=1}^{k} E N S}{\sum_{i=1}^{k} N_{i}}
\end{aligned}
$$

Here,

$N_{i}$ - Number of customers, $U_{i}$ - Annual outage time;

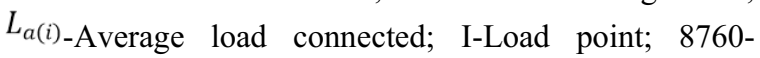
Number of hours in a calendar year.

\section{Wind Turbine Modelling}

Wind turbines cannot operate at maximum limit, The $\mathrm{Cp}$ value is different for each type of turbine, in addition there is a wind speed function that works on the turbine. The actual presence limit is less than the Betz Limit with prices $\mathrm{b} / \mathrm{w} 0.35$ to 0.45 accepted even in high-end airports. By allowing the availability of an additional cutter on a complete wind device that drives a machine system for example a gearbox, bearings, generator and so on Only $10-30 \%$ of of wind Power can be converted into active Power. Wind power occurs approximately at the rate of energy conversion

$$
\mathrm{P}=\frac{d E}{d t}=\frac{1}{2} V^{2} \frac{d m}{d t}
$$

Therefore from Eq. (3), power can be represented as

$$
\mathrm{P}=\frac{1}{2} \rho A V^{3}
$$

The deducible power from the wind is likely by 
$P_{\text {avail }}=\frac{1}{2} \rho A V^{3} C_{p}$

Here,

Cp - Max Power Co-eff (Theoretical Max $=0.59$ )

P- Power Output in KW

A - Rotor Swept Area, $\mathrm{ft} 2$ (or) $\pi \mathrm{r}^{2}$ ( $\mathrm{r}$ is the radius equal to the Blade Length in $\mathrm{ft}, \pi=3.1416$ )

$\rho$ - Air Density in $\mathrm{lb} / \mathrm{ft} 3$

$\mathrm{V}$ - Wind Speed in mph

Calculations: The Projected Wind Turbine Wind Speed$10 \mathrm{~m} / \mathrm{sec}$

Blade length $(l)-30 \mathrm{~m}$

Air Density $(\rho)-1.225 \mathrm{~kg} / \mathrm{m} 3$

Swept Area $(A)-\pi \mathrm{r}^{2}$ is $2828 \mathrm{~m}^{2}$

Power Coeff (Cp)-0.42After that the energy is converted from the air to rotating power generated by the propeller using rating (5)

$$
\begin{aligned}
\text { Pavail } & =\frac{1}{2} * 1.225 * 2828 * 10^{3} * 0.42 \\
& =0.072 \mathrm{MW}
\end{aligned}
$$

\section{Photovoltaic Array Modelling}

With all that in mind an equivalent circuit of PV modules as shown in fig. 1 .

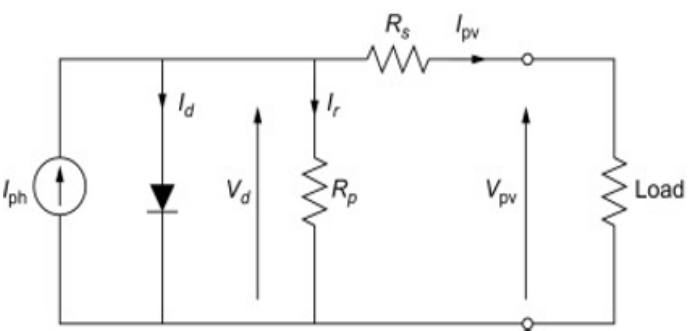

Fig.1 Equivalent circuit of PV module

The given Open circuit voltage is

$V_{o c}=\mathrm{n} V_{r} \ln \left[\frac{I_{P V}}{I_{o}+1}\right]$

Here

$I_{p v-\mathrm{PV} \text { generated current }}$

$n$-no.of modules

$I_{o}$-reverse saturation current

$V_{T}$ - thermal voltage

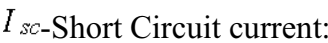

$I_{s c}=I_{P V}-I_{0}\left[\frac{I_{S C} R_{S}}{e^{n V_{T}}-1}\right]-\frac{I_{s c} R_{S}}{R_{s h}}$

Two pairs of working points equal to $\mathrm{I}_{\text {scand }} \mathrm{V}_{\mathrm{oc}}$, energy from a solar cell are present nothing. Fill factor exists as a parameter that, in conjunction with $\mathrm{I}_{\mathrm{sc}}$ and $\mathrm{V}_{\mathrm{oc}}$, stimulate the maximum Power from a solar cell. Another practice of measuring solar cell achievement is the filler element, which is as likely as possible

$$
\text { Fill Factor }=\frac{P_{\max }}{V_{o c} \times I_{s c}}
$$

As a result the maximum power of the solar unit is

$$
P_{\text {max }}=V_{o c} I_{s c} F F
$$

The Solar cell efficiency indicates the degree to which a large energy-producing material at a high energy level is subdivided into light energy from another, which is given as

$$
\eta=\frac{V_{0 C} I_{s c} F F}{P_{i n c}}
$$

The following parameters are correctly installed in the fixed Photovoltaic Panel

$\mathrm{I}_{\mathrm{sc}}=8.33$

$\mathrm{V}_{\mathrm{oc}}=32.97$

$$
\mathrm{FF}=0.7811
$$

Therefore, $P_{\max }=220.76$ Watts

Efficiency estimation of input power is $1 \mathrm{kw} / \mathrm{m}^{2}$ or 100 $\mathrm{mw} / \mathrm{cm}^{2}$. That the intensity of light emanating from the physical parameters of a photovoltaic projected, happens to be calculated as $\mathrm{P}$ inc $=1530 \mathrm{~W}$

Subsequent percentage operation of the photovoltaic module, which may be combined with a radial distribution system $\eta=14 \%$

\section{Results and Considerations}

To prove the impact of the proposed process, it is available in the IEEE 33 Bus Radial distribution system. Two renewable DGs Solar and wind are included in Bus4 and Bus- 6 .

Table.1: System Reliability-Indices

\begin{tabular}{|c|c|c|c|}
\hline $\begin{array}{c}\text { System } \\
\text { Indices }\end{array}$ & $\begin{array}{c}\text { 6-Bus } \\
\text { IEEE } \\
\text { System } \\
\text { Base case } \\
\text { (without } \\
\text { DGs) }\end{array}$ & $\begin{array}{c}\text { 6-Bus } \\
\text { IEEE } \\
\text { System } \\
\text { With } \\
\text { 1DG }\end{array}$ & $\begin{array}{c}\text { 6-Bus } \\
\text { IEEE } \\
\text { System } \\
\text { with 2DGs }\end{array}$ \\
\hline SAIDI & 1.6061 & 1.4466 & 1.4060 \\
\hline SAIFI & 1.0500 & 0.7841 & 0.7030 \\
\hline AENS & 0.1441 & 0.1303 & 0.1279 \\
\hline EENS & 317.0 & 286.6 & 281.2 \\
\hline ACCI & 104.90 & 78.59 & 72.14 \\
\hline ALII & 1.00 & 0.75 & 0.70 \\
\hline CAIDI & 1.530 & 1.845 & 2.000 \\
\hline CTAIDI & 1.606 & 1.447 & 1.406 \\
\hline
\end{tabular}


The Network is built by using ETAP, 2-cases considered and possible compared to the ETAP software shown in Fig.2

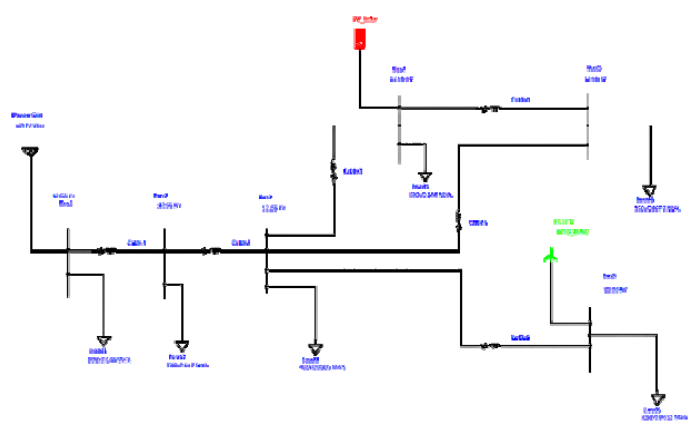

Fig.2 Renewable DGs Integrated to Radial 6-Bus Distribution System.

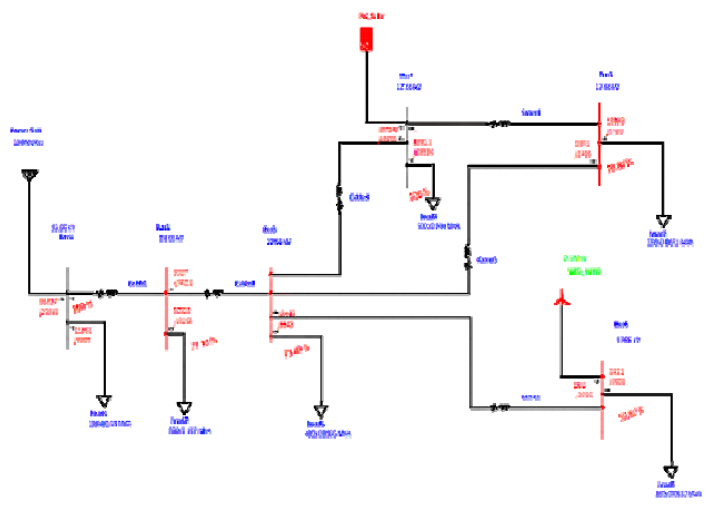

Fig.3 Load Flow analysis of Radial 6-bus Distribution system with DGs

Simulation of the standard IEEE Radial distribution system takes place as load flow studies.In air safety only $14 \%$ of wind energy is converted into available capacity. From the estimated calculation the output volume is calculated by calculating such as $0.072 \mathrm{MW}$ that is $14 \%$ of the Original size or size of a specific Wind DG set with a Capacity of $0.5 \mathrm{MW}$. Power curve of wind turbine, speed compared to power shown in Fig. 5. In the same format of the generated structure, the rated capacity of the Photovoltaic panel is approximately 220.76 Watts / panel according to the theory in phase IV.

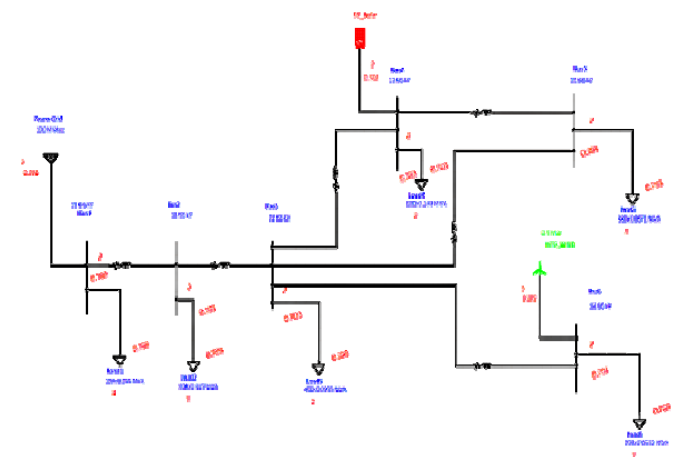

Fig.4 Reliability analysis of Radial Distribution system with
DGs

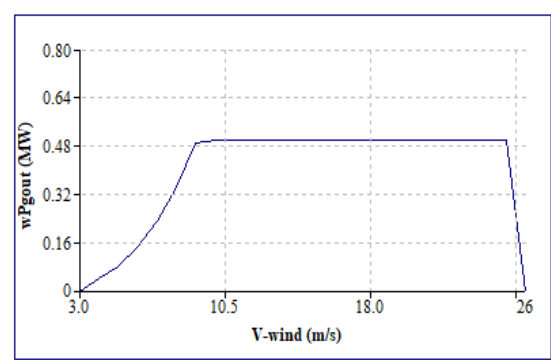

Fig. 5 wind turbine power curve

These existing panels are connected sequentially with the same combination to meet the appropriate size of 1MW DC Photovoltaic Array. The PV and V features of the voltaic photo panel are found as described in Fig. 6 and Fig. 7

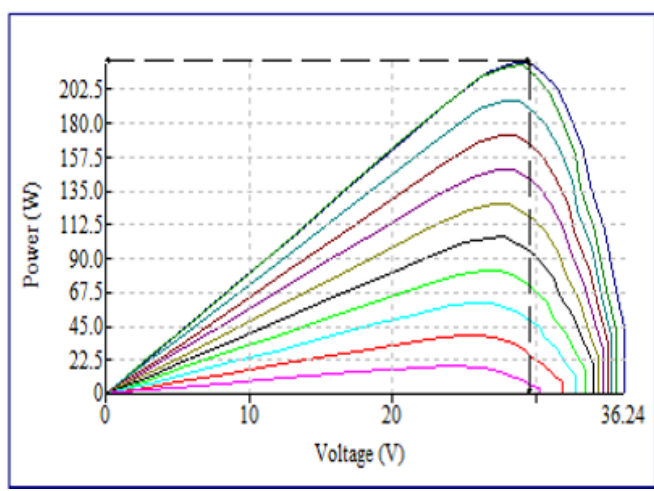

Fig.6 PV characteristics of the Photovoltaic Panel

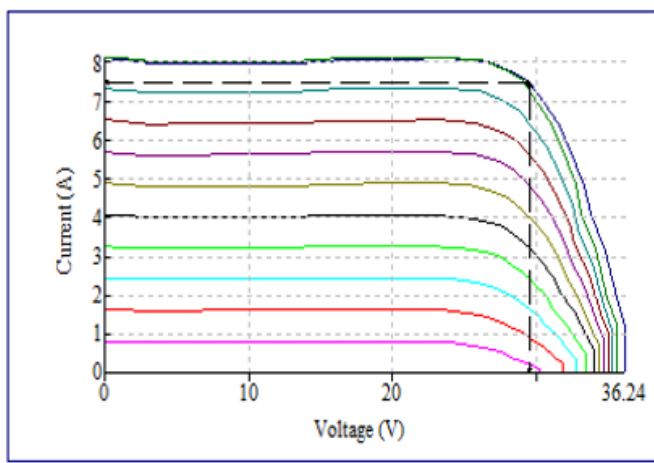

Fig.7 V-I Characteristics of Photovoltaic Panel

Table 2: Size of the Renewable DG's

\begin{tabular}{|c|c|}
\hline Bus No & Renewable DG Size (MW) \\
\hline Bus4 & 1 (Solar) \\
\hline Bus6 & $0.5($ wind) \\
\hline
\end{tabular}


Table 3: Load Flow Analysis Results

\begin{tabular}{|c|c|c|c|}
\hline \multirow{2}{*}{ Cases } & Description & Parameters & Values \\
\hline \multirow{2}{*}{ Case1 } & Base Case & Losses (MW) & 37.303 \\
\cline { 3 - 4 } Case2 & $\begin{array}{c}\text { Integrated with 1 } \\
\text { Renewable DG }\end{array}$ & Losses (MVar) & 12.892 \\
\cline { 3 - 4 } & & Losses(MW) & 25.157 \\
\hline \multirow{2}{*}{ Case3 } & $\begin{array}{c}\text { Thtegrated with 2 } \\
\text { Renewable DGs }\end{array}$ & Losses (MVar) & 10.718 \\
\cline { 3 - 4 } & & Losses (MVar) & 10.461 \\
\hline
\end{tabular}

It is evident that the loss of the Base case occurred at 37.303 MW and at 12,892 Mvar and was found to be reduced in cases 2, 3. Moreover, when separated from additional cases, less power is improved. This shows that the loss is reduced and the definition of power has been improved by the one proposed in Case 3 .

\section{Conclusion}

The pattern of reliable judgment on the availability of Solar DG and Wind DG to reduce extinguishing is examined in this local paper. A new method was developed to determine the exact location and size of the Renewable Distributed Generation (DG) in the distribution system. The reliability process was tested prior to the IEEE 6-Bus Radial Distribution System system in the ETAP Software. In this paper various cases are considered to evaluate the benefits of the proposed system. The results show that especially for the skilled there is a significant reduction in Power loss.

\section{References}

1. V. Usha Rani and J. Sridevi, International Journal of Computer Engineering In Research Trends., 4, (2017).

2. J. Yan, T. Shamim, S. K. Chou, U. Desideri, and H. Li, Appl.Energy, (2016).

3. Mohammad Al-Muhaini and Gerald T. Heydt, IEEE Trans. Power Delivery, 28, (2013).

4. V Shashidhar, DG Padhan, E3S Web of Conferences, (2019).

5. M.HIatshwayo, S.Chowdhury, S.P. Chowdhury and K. 0. Awodele, IEEE Int. Conf. on Power Syst. Tech., (2010).

6. DSNMRAO, D Raveendhra, N Bharath Kumar, P Srividya Devi, D Gireesh Kumar; ECTI Transactions on Electrical Engineering, Electronics, and Communications, 19, (2021).

7. Gozel, T., Hocaoglu, M.H., Electr. Power Syst. Res., (2009).
8. R.N. Allan, R. Billinton, I. Sjarief, L. Goel, K.S., IEEE Trans. on Power Syst., 6, (1991).

9. Roy Billinton, Ronald N. Allan, Springer publications, Hyderabad, (2007).

10. R. S. Rao, K. Ravindra, K. Satish, and S. V. L. Narasimham, IEEE Trans. Power Syst., 28, (2013).

11. D. Q. Hung and N. Mithulananthan, Industrial Electronics, IEEE Transactions on, 60, (2013).

12. Nisha R. Godha, Surekha R. Deshmukh, Rahul and V. Dagade, OTime, ISCI, (2012).

13. T. T. Nguyen and A. V. Truong, International Journal of Electrical Power \& Energy Systems, 68, (2015).

14. R. Rajaram, K. S. Kumar, and N. Rajasekar, ,Energy Reports, 1, (2015).

15. Madhuri,S., Srividya Devi, P.; International Journal of Recent Technology and Engineering, 8, (2019).

16. Nutakki, M., Palakaluri, S.V.D., R.Vijaya Santhi, International Journal of Innovative Technology and Exploring Engineering, 8, (2019).

17. Sai, V.A., Srikanth, B., Devi, P.S., Rajamahanthi.V; IEEE-SeFet (2021).

18. Jayahari, L., Hussaini, S.M., Varmaa.D; Advances in Materials and Processing Technologies, 6, (2020).

19. Srividya Devi.P, R Vijaya Santhi ; International Journal of Electrical and Computer Engineering 9(2019)

20. Zulu Esau and Dilan Jayaweera, J. Mod. Power Syst. Clean Energy, (2014).

21. Radhika, K., Nallamekala, K.K., Venkatraman, K., Padhan, D.G., IEEE-SeFet , (2021).

22. R.R., Nawaz, S.S., Padhan, D.G. 2021, IEEE-SeFet (2021).

23. V Shashidhar, DG Padhan E3S Web of Conferences, (2019). 